PAPER

\section{Electrical characteristics of Au/Ti/n-GaAs contacts over a wide measurement temperature range}

To cite this article: Necmi Biyikli et al 2014 Phys. Scr. 89095804

View the article online for updates and enhancements.
Related content

- Capacitance-conductance characteristics
$\frac{\text { of Au/Ti/Al2O3/n-GaAs structures with }}{\text { very thin Al2O3 interfacial laver }}$
A Turut, A Karabulut, K Ejderha et al.
- Influence of Al2O3 barrier on the
$\frac{\text { interfacial electronic structure of Au/Ti/n- }}{\text { GaAs structures }}$
Abdulkerim Karabulut, Hasan Efeoglu and
Abdulmecit Turut
- Barrier characteristics of Cd/p-GaTe
$\frac{\text { Schottky diodes based on l--V--T }}{\text { measurements }}$
B Abay, G Çankaya, H S Güder et al.

Recent citations

- Silicon based photodetector with Ru(II)
$\frac{\text { complexes organic interlaver }}{\text { Abdulkerim Karabulut et al }}$
- The current-voltage characteristics over
$\frac{\text { the measurement temperature of } 60-400 \mathrm{~K}}{\text { in the Au/Ti/n-GaAs contacts with high }}$
$\frac{\text { dielectric HfO2 interfacial layer }}{\text { Abdulkerim Karabulut et al }}$
- The electrical and dielectric properties of
the Au/Ti/HfO $2 / \mathrm{n}-\mathrm{GaAs}$ structures
A. Karabulut et al




\title{
Electrical characteristics of Au/Ti/n-GaAs contacts over a wide measurement temperature range
}

\author{
Necmi Biyikli ${ }^{1}$, Abdulkerim Karabulut ${ }^{2}$, Hasan Efeolu ${ }^{3}$, Betul Guzeldir ${ }^{4}$ and \\ Abdulmecit Turut $^{5}$ \\ ${ }^{1}$ UNAM Institute of Materials Science and Nanotechnology, Bilkent University, Ankara 06800, Turkey \\ ${ }^{2}$ Ağnı İbrahim Çeçen University, Faculty of Science and Arts, Department of Physics, Ağrı, Turkey \\ ${ }^{3}$ Atatürk University, Faculty of Engineering, Department of Electrical and Electronics Engineering, \\ TR-25240 Erzurum, Turkey \\ ${ }^{4}$ Atatürk University, Faculty of Science, Department of Physics, TR-25240 Erzurum, Turkey \\ ${ }^{5}$ Istanbul Medeniyet University, Faculty of Sciences, Engineering Physics Department, TR-34730 Istanbul, \\ Turkey
}

E-mail: amecit2002@yahoo.com and abdulmecit.turut@medeniyet.edu.tr

Received 9 October 2013, revised 15 April 2014

Accepted for publication 16 June 2014

Published 1 August 2014

\begin{abstract}
We have fabricated $\mathrm{Au} / \mathrm{Ti} / \mathrm{n}-\mathrm{GaAs} / \mathrm{In}$ Schottky barrier diodes using the magnetron dc sputter technique. The capacitance-temperature $(C-T)$ measurements with bias voltage as a parameter and the current-voltage $(I-V)$ and capacitance-voltage $(C-V)$ measurements have been made in the temperature range of 60-300 K. The temperature-dependent capacitance measurements have been made at $1.0 \mathrm{MHz}$. The capacitance versus temperature curve at each bias voltage has four regions with slopes different from each other. The capacitance decreases with a decrease in temperature at each bias voltage. Such a temperature-dependent behavior could be attributed to modulation of the space charge region caused by the emission of deep-level impurities or interface states. The carrier concentration calculated in the -1.0 to $-2.0 \mathrm{~V}$ range of $C^{-2}-V$ plots was close to the value of $7.43 \times 10^{15} \mathrm{~cm}^{-3}$ given by the manufacturer around room temperature. The ideality factor value from the $I-V$ characteristics has remained almost unchanged between 1.07 and 1.10 in the temperature range of $150-300 \mathrm{~K}$, indicating that the current across the device obeys the thermionic emission current model quite well over the whole bias range at temperatures above $150 \mathrm{~K}$. Therefore, the conventional Richardson plot in this temperature range has given a Richardson constant of $8.21 \mathrm{~A}\left(\mathrm{~cm} \mathrm{~K}^{-2}\right.$, within experimental error, which is in very close agreement with the theoretical value of $8.16 \mathrm{~A}(\mathrm{~cm} \mathrm{~K})^{-2}$ for $\mathrm{n}$-type GaAs. Again, it has been seen that the ideality factor with the values of 1.10 at $150 \mathrm{~K}$ and 1.22 at $60 \mathrm{~K}$ does not show a considerable decrease. The experimental parameters show that the $\operatorname{Au}(90 \mathrm{~nm}) / \mathrm{Ti}(10 \mathrm{~nm}) / \mathrm{n}$ GaAs contact is a good candidate for electronic device applications.
\end{abstract}

Keywords: metal semiconductor contacts, GaAs semiconductor, thermionic emission

(Some figures may appear in colour only in the online journal)

\section{Introduction}

Metal-semiconductor (MS) rectifying or ohmic contacts are of great importance for device applications such as organic photovoltaic solar cells, $\mathrm{p}-\mathrm{n}$ junctions, bipolar transistors, metal-semiconductor field effect transistors (MESFETs) and high-electron mobility transistors (HEMTs) [1-3]. The MS contact theory serves as the foundation of the physics of semiconductor devices in modern electronic applications and in understanding other semiconductor devices [1-7]. The 
refractory metal gate technology has been used for the fabrication of high-speed MESFETs to reduce the parasitic overlap capacitances between gate and source and series resistance and thus to improve the speed-power performance [5-9]. The occupancy of substrate traps is affected by temperature variations, illumination, or irradiation, and this is true of the space charge region. For this reason, the variation of device parameters over a wafer may arise from the nonuniform distribution of traps in the wafer as well as the interface states [1-7].

Schottky contacts play an important role in controlling the electrical performance of devices. Sehgal et al [10, 11] have investigated the thermal stability of $\mathrm{Au} / \mathrm{Pt} / \mathrm{Ti}$ Schottky contacts on $\mathrm{n}-\mathrm{GaAs}$ with Ti films of $0-60 \mathrm{~nm}$. They have found $[10,11]$ that by introducing the Ti film between GaAs and $\mathrm{Au} / \mathrm{Pt}$ the interdiffusion of $\mathrm{Pt}$ and $\mathrm{Au}$ is also prevented. These results are useful for reducing the gate metallization resistance of MESFET transistors, and these contacts can next be used to fabricate submicrometer gate length GaAs MESFETs. Arulkumaran et al [12] have analyzed silicon doped Ti/ $\mathrm{n}$-GaAs Schottky barrier diodes (SBDs) formed by the evaporation method and obtained a barrier height $(\mathrm{BH})$ of $0.78 \mathrm{eV}$ for these diodes at room temperature. Dio et al [13] have reported forward and reverse current-voltage $(I-V)$ characteristics for $\mathrm{Ti} / \mathrm{GaAs}$ diodes prepared by ion beam sputtering, and they have shown [13] that the $I-V$ analysis in the temperature range of $100-360 \mathrm{~K}$ indicates that the thermionic emission (TE) is the main transport mechanism for all the samples, although there are deviations from this behavior at low temperature. They have obtained [13] an average of $0.81 \mathrm{eV}$ for $\mathrm{Ti} / \mathrm{n}-\mathrm{GaAs}$ diodes prepared at different sputtering voltages and currents, and have interpreted the departure from ideal conditions as a direct effect of $\mathrm{BH}$ inhomogeneities at the metal-semiconductor interface. Therefore, the performance of GaAs based devices especially depends on the surface and interface defect density, series resistance, temperature and applied bias voltage [1-9].

We have investigated measurement temperature capacitance-voltage $(C-V)$ and $I-V$ characteristics of $\mathrm{Au} / \mathrm{Ti} / \mathrm{n}$ GaAs/In SBDs in the measurement temperature range of $60-300 \mathrm{~K}$. We have fabricated the $\mathrm{Au} / \mathrm{Ti} / \mathrm{n}-\mathrm{GaAs} / \mathrm{In}$ diodes using the magnetron dc sputter technique. The Au thin films have been used as a top layer to protect the Ti metallic layer on the GaAs substrate [14]. As mentioned by Forment et al [15], gallium arsenide is an important semiconductor for optoelectronics, fast computers and microwave applications and $\mathrm{Ti} / \mathrm{n}$-GaAs yields a high barrier. As is well known, if the following current in a Schottky barrier obeys the thermionic emission current model quite well in a given temperature range, the experimental conventional Richardson plot of the saturation currents in this temperature range should give an expected Richardson constant (RC) value for the semiconductor substrate which is in very close agreement with the theoretical value within experimental error. Our purpose is to investigate whether the experimental conventional $\mathrm{RC}$ value of the semiconductor substrate used in the fabrication of such a Schottky diode really is in very close agreement with the theoretical RC value or not, and moreover to show

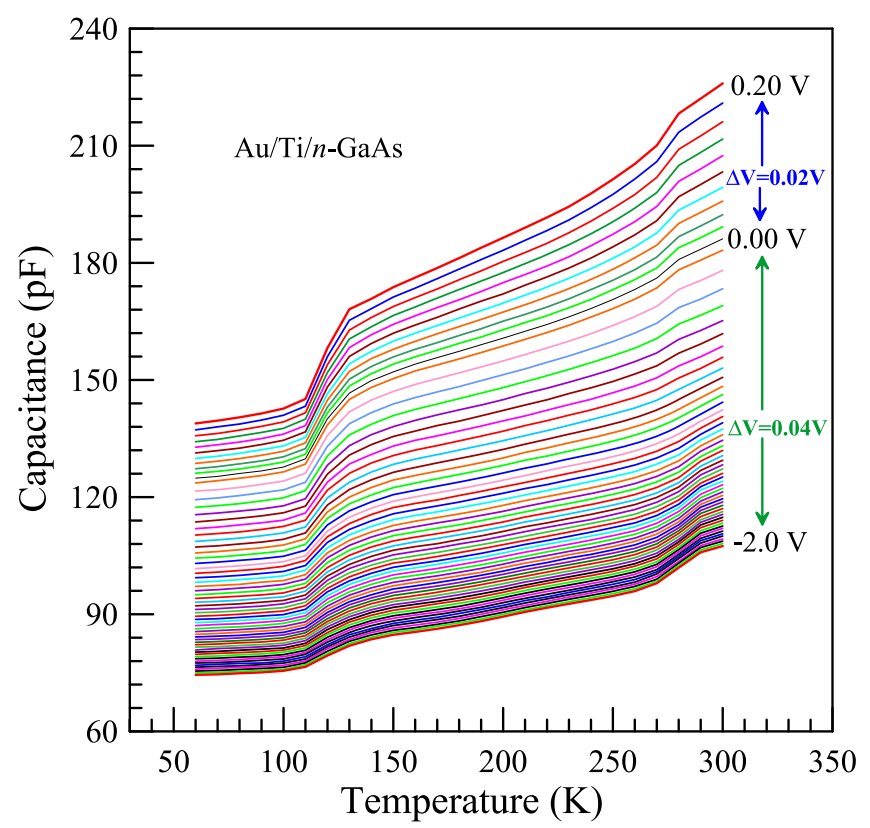

Figure 1. Experimental capacitance plots as a function of the temperature with bias voltage as a parameter at $1.0 \mathrm{MHz}$.

experimentally how the device capacitance under the bias voltage changes with the temperature.

\section{Experimental details}

The $\mathrm{Au} / \mathrm{Ti} / \mathrm{n}-\mathrm{GaAs}$ SBDs structures were fabricated using an n-type single crystal GaAs wafer with (100) surface orientation, having $400 \mathrm{~mm}$ thickness, 2 inch diameter, $7.43 \times 10^{15} \mathrm{~cm}^{-3}$ carrier concentration and $1.2 \Omega \mathrm{cm}$ resistivity (given by the manufacturer). Then, the wafer was rinsed in DI water of $18 \mathrm{M} \Omega \mathrm{cm}$ resistivity for an extended time and dried under $\mathrm{N}_{2}$ flow. After surface cleaning of the $\mathrm{n}-\mathrm{GaAs}$, high purity $(99.999 \%)$ indium with a thickness of about $2000 \AA$ was coated with at a pressure of about $10^{-6}$ Torr in a high vacuum system. To form a good ohmic contact, the nGaAs wafer with the ohmic contact was annealed at $385^{\circ} \mathrm{C}$ for 3 min under $\mathrm{N}_{2}$ atmosphere. For the Schottky contacts, the $\mathrm{n}$-GaAs wafer was placed on a rotating table. Ti $(10 \mathrm{~nm})$ Schottky contacts are made using the magnetron dc sputter technique, and $\mathrm{Au}(90 \mathrm{~nm})$ was evaporated as a top layer on the $\mathrm{Ti} / \mathrm{n}-\mathrm{GaAs}$ structure to protect the Ti metallic layer in high vacuum system of $10^{-6}$ Torr. Ti and Au Schottky contacts were squares with $0.01 \mathrm{~cm}^{2}$ area. After the fabrication process, the $I-V$ characteristics of the $\mathrm{Au} / \mathrm{Ti} / \mathrm{n}-\mathrm{GaAs}$ were measured using a Keithley 2400 SourceMeter. All measurements were made in the temperature range of $60-300 \mathrm{~K}$ using a temperature controlled Janis vpf- 475 cryostat, which enables us to make measurements in the temperature range of $20-450 \mathrm{~K}$. The sample temperature was always monitored by use of a copper-constantan thermocouple close to the sample and measured with a Keithley model 199 DMM scanner and Lakeshore model 321 auto-tuning temperature controller with sensitivity better than $\pm 0.1 \mathrm{~K}$. 


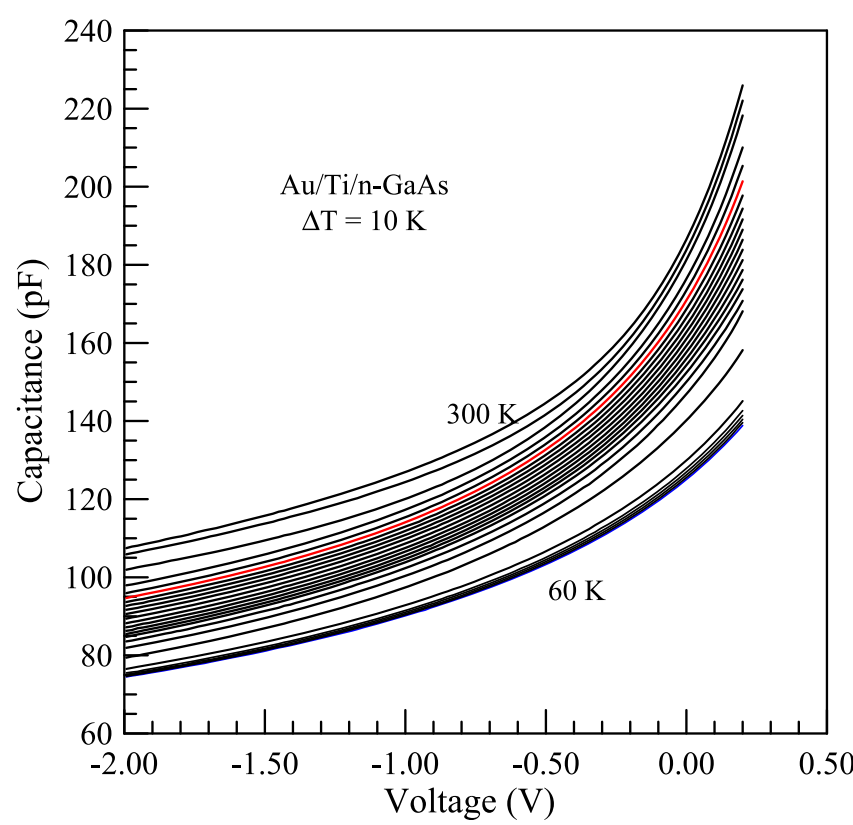

Figure 2. Capacitance-voltage curves for the $\mathrm{Au} / \mathrm{Ti} / \mathrm{n}-\mathrm{GaAs}$ structure at $1.0 \mathrm{MHz}$ in the temperature range of $60-300 \mathrm{~K}$.

\section{Results and discussion}

Figure 1 shows the experimental capacitance versus temperature curves for the $\mathrm{Au} / \mathrm{Ti} / \mathrm{n}-\mathrm{GaAs} \mathrm{SBD}$, where the capacitance is a function of the measurement temperature with the bias voltage as a parameter at $1.0 \mathrm{MHz}$. The capacitance decreases with a decrease in temperature at each voltage. It can be seen from figure 1 that there are four regions with different slopes from 60 to $300 \mathrm{~K}$ at each bias voltage. It can be said that the deep level or interface states with different densities and energies affect each region. The slopes decrease with bias voltage decreasing from +0.20 to $-2.0 \mathrm{~V}$. That is, the slopes at $-2.0 \mathrm{~V}$ are lower than those at $+0.20 \mathrm{~V}$, depending on the measurement temperature. Such a temperature-dependent behavior of the capacitance could be attributed to modulation of the space charge region caused by the emission of more carriers from the required levels such as deep-level impurities or interface states $[2,3,16]$. As is known, the capacitance value decreases or approaches the space charge capacitance because the interface states or deep levels cannot follow the ac signal at sufficiently high frequencies [2, 3, 16-19].

As is well known, a $C-V$ plot in the idealized case should show an increase in capacitance with increasing forward voltage independent of temperature and frequency. However, the experimental results had shown that the capacitance in the $C-V$ plot might be influenced by the nonidealities $[2,3,17-23]$. Figure 2 shows the $C-V$ characteristics of the $\mathrm{Au} / \mathrm{Ti} / \mathrm{n}-\mathrm{GaAs} \mathrm{SBD}$ at $1.0 \mathrm{MHz}$ in the temperature range of $60-300 \mathrm{~K}$ with steps of $10 \mathrm{~K}$. The $C-V$ characteristics were measured in +0.20 to $-2.0 \mathrm{~V}$ range at each temperature, where the forward bias branch ranges from 0.00 to $0.20 \mathrm{~V}$, and the reverse bias branch ranges from 0.00 to $-2.0 \mathrm{~V}$. As can be seen from figure 2, the decrease in capacitance in the reverse

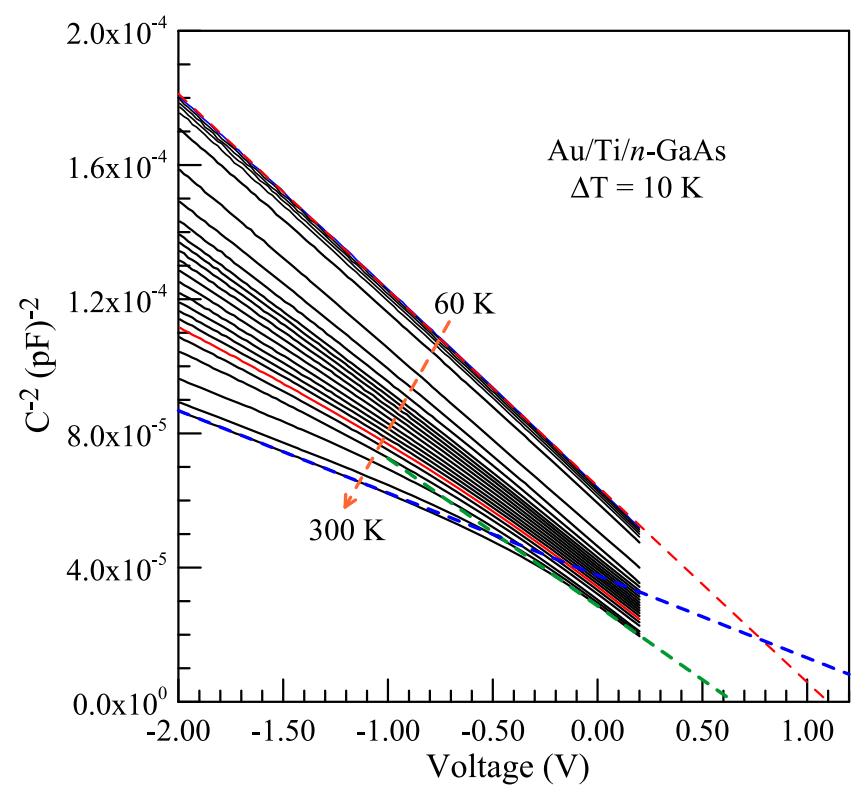

Figure 3. $C^{-2}-V$ plots for the $\mathrm{Au} / \mathrm{Ti} / \mathrm{n}-\mathrm{GaAs}$ structure at $1.0 \mathrm{MHz}$ in the temperature range of $60-300 \mathrm{~K}$.

bias from 0.00 to $-2.00 \mathrm{~V}$ implies an increase in the semiconductor depletion width. Since the charge neutrality condition at the interface should be satisfied, widening of the depletion width in the reverse bias $C-V$ characteristics results from a reduction of the ionized donor concentration.

Figure 3 shows the reverse and forward bias $C^{-2}-V$ curves from the data in the temperature range of $60-300 \mathrm{~K}$ in figure 2. The $C^{-2}-V$ curves show two linear regions separated by a transition segment, especially from 300 to $130 \mathrm{~K}$. That is, the curves have two slopes in the temperature range of $130-300 \mathrm{~K}$ and then trend approximately to have a single slope over the whole voltage range with decreasing temperature. The constant slope yields a uniform doping concentration. This behavior may be due to a change of the carrier concentration profile depending on the sample temperature. The straight line intercepts of the $C^{-2}-V$ plots with the voltage axis were obtained from both linear regions at each temperature. The $C-V \mathrm{BH}$ and carrier concentration values are determined from intercepts and slopes of the straight lines in the $C^{-2}-V$ plots for each temperature. These values are given in figures 3 and 4 .

Figure 4 shows the carrier concentrations calculated from the two present slopes at each temperature in figure 2. As seen from figure 4 , the difference between the carrier concentrations for the two regions decreases with decreasing temperature. It can be said that the carrier concentration has almost the same value from 60 to $120 \mathrm{~K}$. For example, the carrier concentration is $3.21 \times 10^{15}$ and $3.10 \times 10^{15} \mathrm{~cm}^{-3}$ at $60 \mathrm{~K}$ while it is $7.48 \times 10^{15}$ and $4.53 \times 10^{15} \mathrm{~cm}^{-3}$ at $300 \mathrm{~K}$ for the two mentioned regions in figure 3 . Furthermore, the carrier concentration decreases with a decrease in temperature because more electrons may be frozen at the required state levels in the freeze-out region, and it remains almost constant from 60 to $120 \mathrm{~K}$. Moreover, the value of $7.48 \times 10^{15} \mathrm{~cm}^{-3}$ 


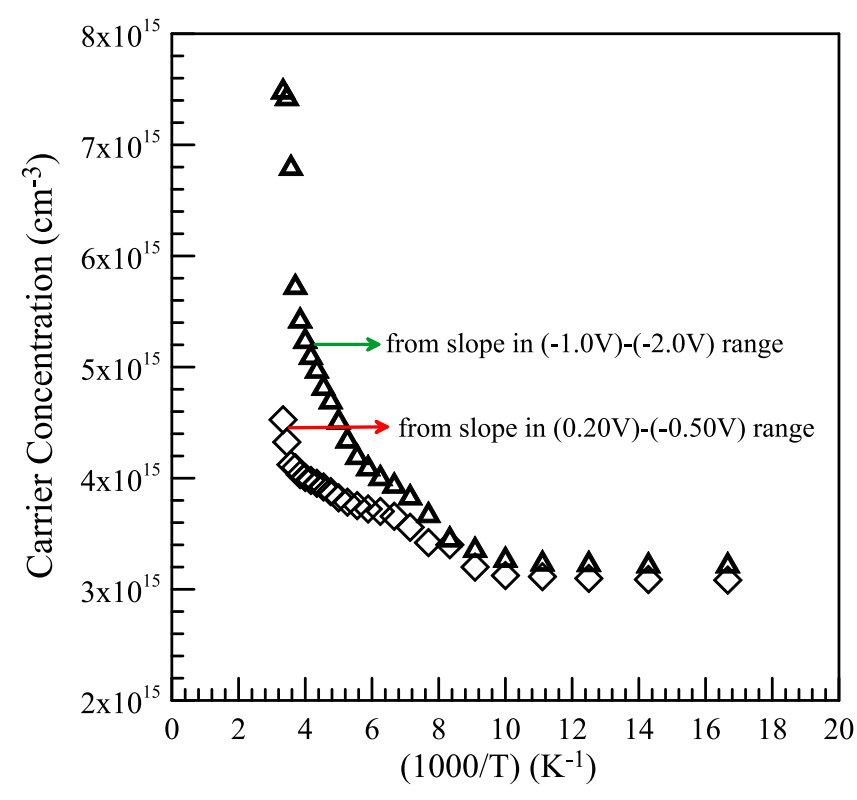

Figure 4. Carrier concentration plots obtained from two regions for the $\mathrm{Au} / \mathrm{Ti} / \mathrm{n}-\mathrm{GaAs}$ structure in the temperature range of $60-300 \mathrm{~K}$.

from the slope in the -1.0 to $-2.0 \mathrm{~V}$ range at $300 \mathrm{~K}$ is in close agreement with the value of $7.43 \times 10^{15} \mathrm{~cm}^{-3}$ given by the manufacturer. Thus, when these values and figure 3 are considered, it can be said that the slope in the $-1.0-0.0 \mathrm{~V}$ range becomes more pronounced with increasing temperature. That is, it can be said that the bulk deep levels or interface states are more effective and they lead to reduction of the carrier concentration in about the $-1.0-0.0 \mathrm{~V}$ range at each temperature above $120 \mathrm{~K}$. In addition to these, it was found by Vandenbroucke [22] that a large density of donor-like defects for the diodes with a sputter-deposited metal contact is present in the near-surface region, together with a region of decreasing density deeper into the semiconductor. These donor-like states in the surface region, induced during bombardment of the substrate, are believed to be responsible for the observed electrical behavior [3]. The carrier concentration remains almost constant as the temperature is decreased from 60 to $120 \mathrm{~K}$. More electrons may be frozen at the donor level in the freeze-out region.

As mentioned above, figure 5 shows the obtained $C-V$ $\mathrm{BH}$ values (open triangles) from the $C^{-2}-V$ plots for each temperature. The $\mathrm{BH}$ value has linearly increased from $0.81 \mathrm{eV}$ at $300 \mathrm{~K}$ to $0.89 \mathrm{eV}$ at $120 \mathrm{~K}$, and has deviated from linearity at temperatures below $120 \mathrm{~K}$. The temperature coefficient of the $\mathrm{BH}$ can be determined from this plot. The temperature dependence of the $\mathrm{BH}$ is expressed as $\Phi(T)=\Phi(T=0)-\alpha T$. According to the equation, the slope of the straight line yields a value of $\alpha=-0.54 \mathrm{meV} \mathrm{K}^{-1}$, called the temperature coefficient value of the $\mathrm{BH}$. Passler [23], Thurmond [24] and Lautenschlager et al [25] indicated the values of $-0.472,-0.5405$ and $-0.55 \mathrm{meV} \mathrm{K}^{-1}$ for the temperature coefficient of the energy band gap of n-type GaAs, respectively. The variation of the $\mathrm{BH}$ value with temperature is normally explained within the frame of the

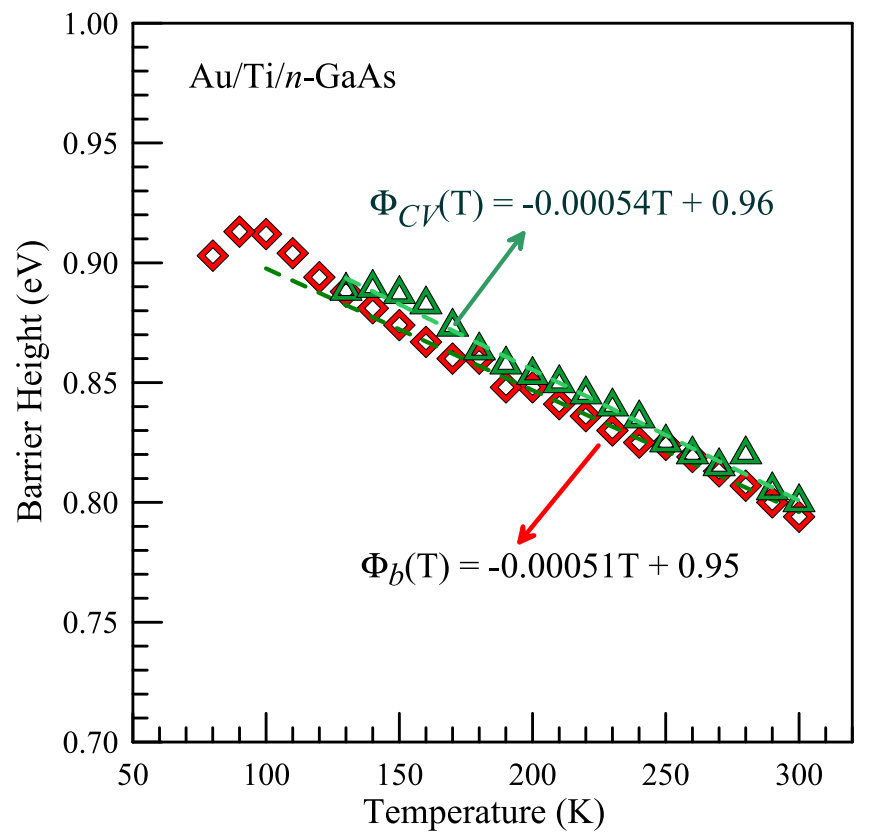

Figure 5. BH versus temperature plot for the $\mathrm{Au} / \mathrm{Ti} / \mathrm{n}-\mathrm{GaAs}$ Schottky barrier diode: open triangles, the $\mathrm{BH}$ values in the 0.00 to $-0.80 \mathrm{~V}$ range of the $C^{-2}-V$ curves at each temperature; open squares, the $\mathrm{BH}$ values from the Norde plot (figure 10) plotted using the forward bias $I-V$ data in figure 6 . The dashed lines are fits to the experimental data.

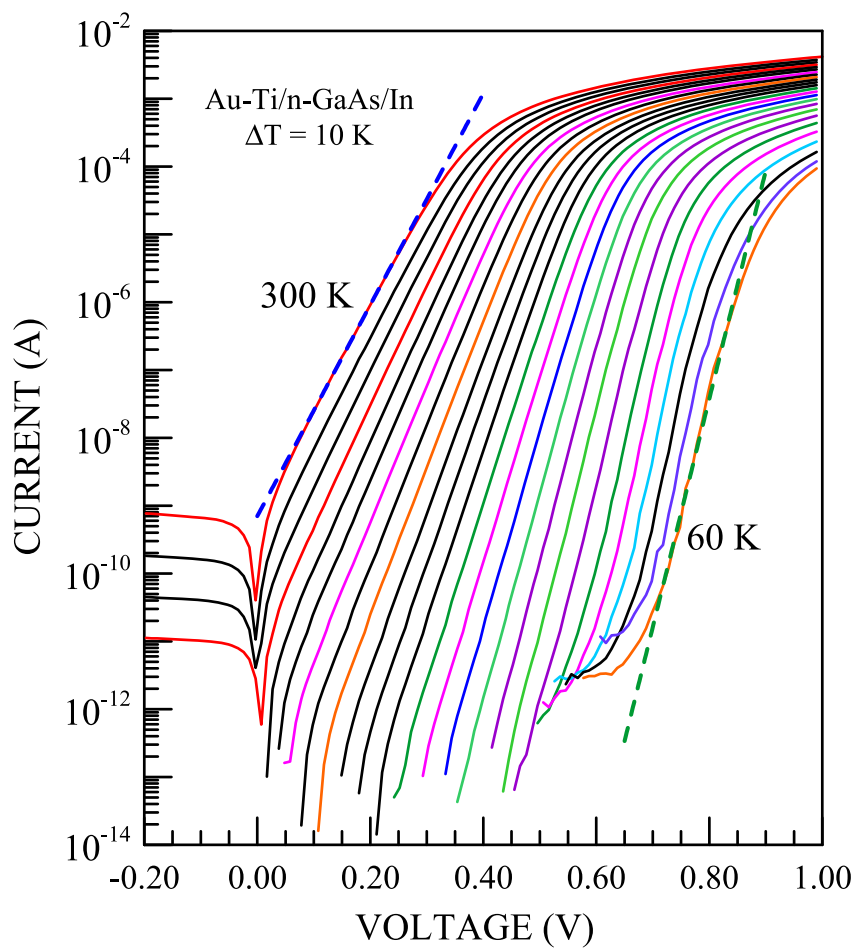

Figure 6. Current-voltage curves for the $\mathrm{Au} / \mathrm{Ti} / \mathrm{n}-\mathrm{GaAs}$ structure in the temperature range of $60-300 \mathrm{~K}$.

Fermi level pinning concept due to the temperature dependent variation in the band gap [24, 25]. The temperature coefficient of the $\mathrm{BH}$ obtained by us is approximately equal to the temperature coefficient of the energy gap of n-type GaAs. 


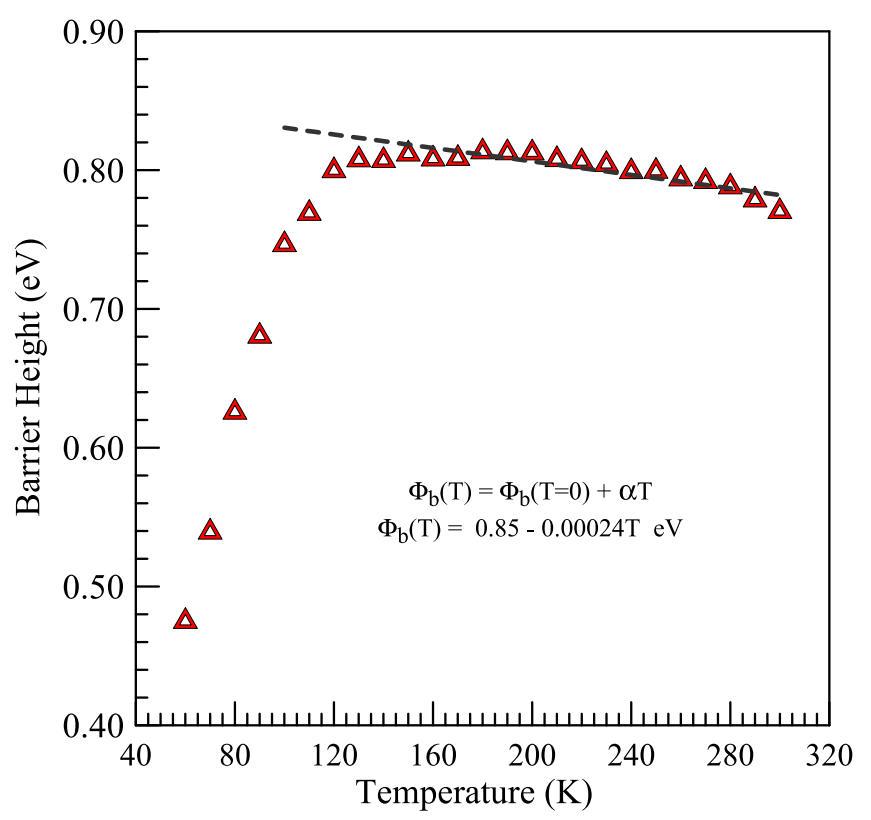

Figure 7. Barrier height versus measurement temperature plot for $\mathrm{Au} / \mathrm{Ti} / \mathrm{n}-\mathrm{GaAs}$ structure in the temperature range of $60-300 \mathrm{~K}$. The dashed straight line shows a fit to experimental data in the $130-300 \mathrm{~K}$ range.

Figure 6 shows the semi-log current-voltage curves of the $\mathrm{Au} / \mathrm{Ti} / \mathrm{n}-\mathrm{GaAs}$ Schottky barrier diode in the temperature range of $60-300 \mathrm{~K}$. The experimental values of the ideality factor and SBH have been calculated from the intercept and slope of the linear portion of the forward-bias $\ln I-V$ plot at each temperature in figure 6 . The intercept of the linear portion corresponds to the saturation current at $V=0$ volts. Figure 7 shows the SBH versus measurement temperature plot for the device in the temperature range of 60-300 K. The $\mathrm{SBH}$ value has increased from $0.77 \mathrm{eV}$ at $300 \mathrm{~K}$ to $0.81 \mathrm{eV}$ at $180 \mathrm{~K}$ with a slope of $-0.24 \mathrm{mV} \mathrm{K}^{-1}$, and has remained almost at the same value as $0.81 \mathrm{eV}$ in the $130-180 \mathrm{~K}$ range. The dashed straight line in figure 7 shows a fit to experimental data in the 130-300 K range. Again, the $\mathrm{BH}$ value has sharply decreased from $0.82 \mathrm{eV}$ at $130 \mathrm{~K}$ to $0.48 \mathrm{eV}$ at $60 \mathrm{~K}$. The decrease of the $\mathrm{BH}$ in the $60-130 \mathrm{~K}$ range is in very close agreement with the results obtained in [26-29]. It has been mentioned in [26] that the $\mathrm{BH}$ is not temperature dependent but rather the current transport mechanisms. In fact, the current processes are temperature dependent and consequently the extraction of the $\mathrm{BH}$ indicates that the $\mathrm{BH}$ changes with temperature [26]. When varying the temperature different current mechanism changes too [26].

The ideality factor value of the device has remained almost unchanged between 1.07 and 1.10 in the temperature range of $150-300 \mathrm{~K}$, and has decreased from 1.10 at $150 \mathrm{~K}$ to 1.22 at $60 \mathrm{~K}$. These values are given in table 1 . Göksu et al [9] obtained the $\mathrm{BH}$ and ideality factor values of 0.62 and 1.61 (at $60 \mathrm{~K}$ ) and 0.91 and 1.02 (at $320 \mathrm{~K}$ ) for Ti/n-GaAs SBDs without an Au layer prepared by magnetron DC sputtering, respectively. Arulkumaran et al [12] have obtained a $\mathrm{BH}$ of $0.78 \mathrm{eV}$ at room temperature for $\mathrm{Ti} / \mathrm{n}-\mathrm{GaAs}$ SBDs formed by the evaporation method. Dio et al [13] have
Table 1. The diode parameters from forward bias $I-V$ characteristics: $\Phi_{\mathrm{b}}$, barrier height; $n$, ideality factor; $I_{0}$, saturation current.

\begin{tabular}{lccc}
\hline Temperature $(\mathrm{K})$ & $\Phi_{\mathrm{b}}(\mathrm{eV})$ & $n$ & $I_{0}$ \\
\hline 300 & 0.770 & 1.074 & $6.81 \times 10^{-10}$ \\
290 & 0.779 & 1.063 & $1.64 \times 10^{-10}$ \\
280 & 0.788 & 1.059 & $3.40 \times 10^{-11}$ \\
270 & 0.792 & 1.042 & $8.00 \times 10^{-12}$ \\
260 & 0.794 & 1.052 & $1.84 \times 10^{-12}$ \\
250 & 0.799 & 1.054 & $3.20 \times 10^{-13}$ \\
240 & 0.799 & 1.050 & $6.40 \times 10^{-14}$ \\
230 & 0.804 & 1.048 & $8.44 \times 10^{-15}$ \\
220 & 0.806 & 1.049 & $1.1 \times 10^{-15}$ \\
210 & 0.808 & 1.058 & $1.22 \times 10^{-16}$ \\
200 & 0.812 & 1.052 & $9.00 \times 10^{-18}$ \\
190 & 0.813 & 1.061 & $6.81 \times 10^{-19}$ \\
180 & 0.813 & 1.074 & $3.70 \times 10^{-20}$ \\
170 & 0.808 & 1.077 & $2.10 \times 10^{-21}$ \\
160 & 0.808 & 1.098 & $6.10 \times 10^{-23}$ \\
150 & 0.812 & 1.104 & $8.2 \times 10^{-25}$ \\
140 & 0.807 & 1.130 & $1.20 \times 10^{-26}$ \\
130 & 0.807 & 1.183 & $5.80 \times 10^{-29}$ \\
120 & 0.800 & 1.150 & $2.60 \times 10^{-31}$ \\
110 & 0.769 & 1.230 & $5.00 \times 10^{-33}$ \\
100 & 0.746 & 1.280 & $1.7 \times 10^{-35}$ \\
90 & 0.680 & 1.438 & $4.51 \times 10^{-36}$ \\
80 & 0.626 & 1.601 & $1.73 \times 10^{-37}$ \\
70 & 0.539 & 1.926 & $5.10 \times 10^{-37}$ \\
60 & 0.475 & 2.221 & $3.30 \times 10^{38}$ \\
\hline & & & \\
\hline & &
\end{tabular}

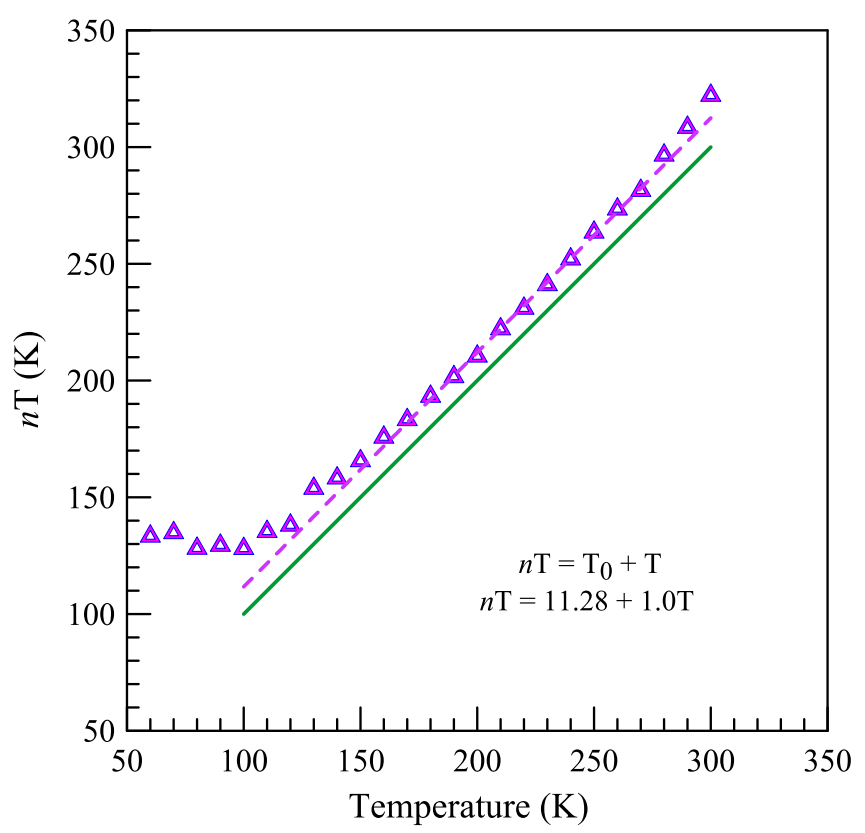

Figure 8. $n T$ versus $T$ plot showing the $T_{0}$ anomaly for the $\mathrm{Au} / \mathrm{Ti} / \mathrm{n}$ GaAs structure in the temperature range of $60-300 \mathrm{~K}$. The solid line is ideal Schottky diode behavior given as ideality factor $n=1$; the dashed straight line shows a fit to experimental data.

obtained an average of $0.81 \mathrm{eV}$ for $\mathrm{Ti} / \mathrm{n}-\mathrm{GaAs}$ diodes prepared at different sputtering voltages and currents. The values of the ideality factor near unity indicate that the experimental $I-V$ data obey the TE current model quite well over the whole 


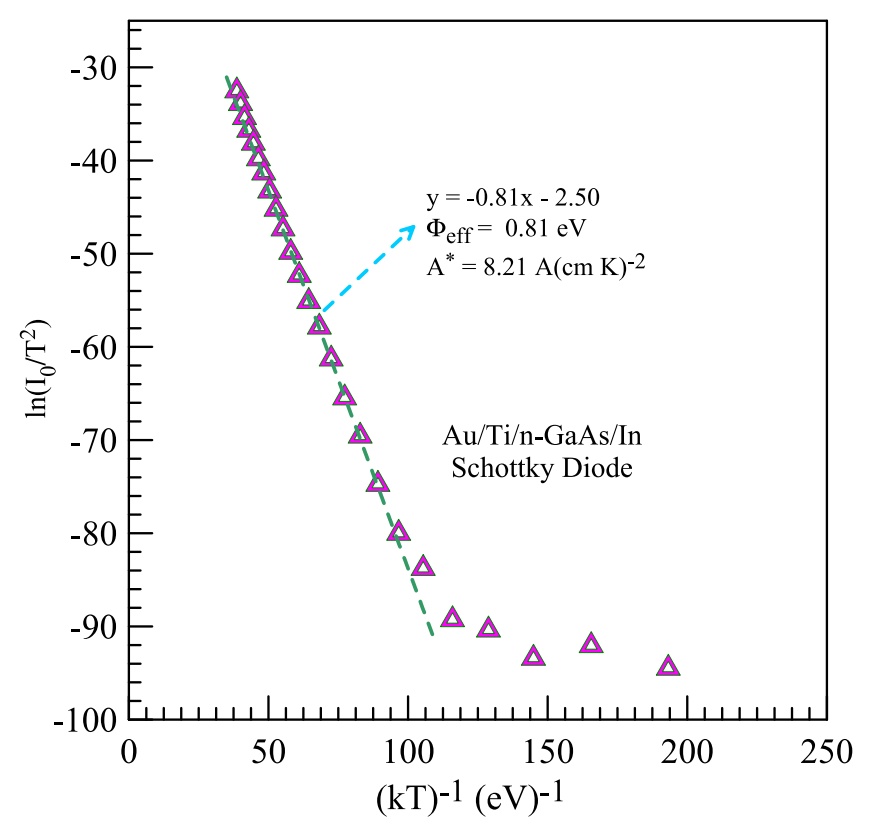

Figure 9. Conventional Richardson plot for the $\mathrm{Au} / \mathrm{Ti} / \mathrm{n}-\mathrm{GaAs}$ structure in the temperature range of $60-300 \mathrm{~K}$.

bias range at temperatures above $150 \mathrm{~K}$. The values of the SBH and ideality factor have been calculated using equation (1) and (2), called the TE current relationships, given in [1-3]. The case can be seen more clearly in figure 8 , which shows the $n T$ versus $T$ plot for Au/Ti/n-GaAs in the temperature range of $60-300 \mathrm{~K}$. This is called the $T_{0}$ anomaly plot determining the temperature dependence of the ideality factor $n$. The solid line in figure 8 is ideal Schottky diode behavior given as $n=1$, which goes through the origin. The dashed straight line fitted to experimental data for information about the $T_{0}$ effect should be parallel to the ideal Schottky line. A value of $T_{0}=11.28 \mathrm{~K}$ was obtained from the experimental plot. As can be seen from figure 8, the dashed straight line significantly deviates from linearity below 120 or $130 \mathrm{~K}$. It has been pointed out in [27-33] that the change at low temperatures may be ascribed to the current flow through small regions, so-called 'patches', with low BH. The conventional Richardson $\ln \left(I_{0} / T^{2}\right)$ versus $(k T)^{-1}$ plot in the temperature range of $60-300 \mathrm{~K}$ in figure 9 is linear in the $120-300 \mathrm{~K}$ range, where $I_{0}$ is the saturation current in the TE current expression [1-3]. Therefore, it has given an RC of $8.21 \mathrm{~A}$ $(\mathrm{cm} \mathrm{K})^{-2}$ from the conventional Richardson plot (figure 9), within experimental error. This value is in very close agreement with the theoretical value of $8.16 \mathrm{~A}(\mathrm{~cm} \mathrm{~K})^{-2}$ for n-type GaAs. Thus, it can be said that the $I-V$ characteristics of the device obey the TE current model in the $120-300 \mathrm{~K}$ range [34-41].

As is well known, when the MS Schottky diodes are characterized by $I-V$ and $C-V$ data, the $\mathrm{BH}$ calculated from the $C-V$ data is higher than the $\mathrm{BH}$ value extracted from the saturation current of the semi-log forward bias characteristics and gives an average value of the BHs of the patches present in the Schottky contact. The mentioned saturation current is the intercept of the linear portion of the semi-log forward bias

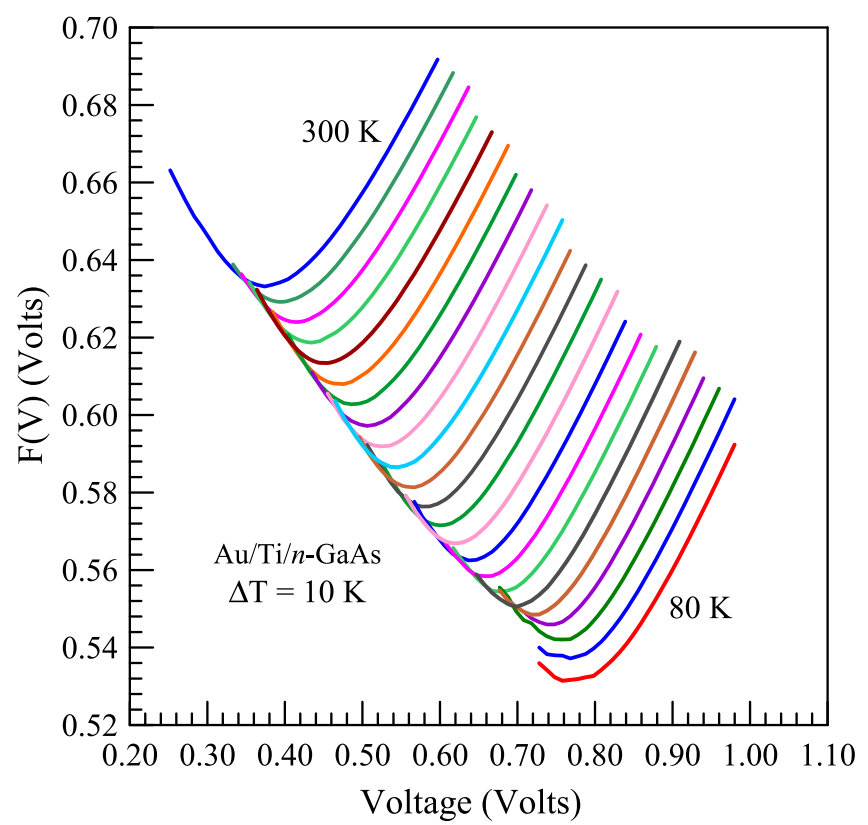

Figure 10. Norde plot for the $\mathrm{Au} / \mathrm{Ti} / \mathrm{n}-\mathrm{GaAs}$ Schottky barrier diode in the temperature range of $60-300 \mathrm{~K}$.

curve. Osvald [33] says that the $I-V$ and $C-V$ measurement techniques are differently sensitive to possible occurrence in the inhomogeneous Schottky contacts at especially low temperatures. Because the current of the Schottky diode depends exponentially on the $\mathrm{BH}$, the inhomogeneities and small patches with lower $\mathrm{BH}$ in the contact strongly influence the resulting apparent $\mathrm{BH}$ [28-41].

The $\mathrm{BH}$ of the $\mathrm{Au} / \mathrm{Ti} / \mathrm{n}-\mathrm{GaAs} / \mathrm{In}$ can be also calculated by Norde's method [42], because the device shows an ideal behavior. A function $F(V)$ was derived from the TE current expression by Norde [40]:

$$
F(V)=\frac{V}{\gamma}-\frac{k T}{q} \ln \left(\frac{I(V)}{A A^{*} T^{2}}\right),
$$

where the current $I(V)$ is obtained from the $I-V$ curves at each temperature in figure 6 . This function can be used to determine the $\mathrm{BH}$ [42]. Figure 10 shows the $F(V)$ versus $V$ plots obtained using the experimental $I-V$ data in equation (1). The $\mathrm{BH}$ relation is given as follows [38]:

$$
\Phi(T)=F\left(V_{\min }\right)+\frac{V_{\min }}{2}-\frac{k T}{q},
$$

where $F\left(V_{\min }\right)$ is the minimum value of $F(V)$ and the corresponding voltage and current are $V_{\min }$ and $I_{\min }$, respectively. The $\mathrm{BH}$ values from the $F(V)-V$ curves are given as a function of temperature in figure 4 (indicated by open squares). The expressions (1) and (2), which are called Norde's functions, are based on the TE current mechanism [2, 3, 42, 43]. The $\mathrm{BH}$ value has linearly increased from $0.81 \mathrm{eV}$ at $300 \mathrm{~K}$ to $0.89 \mathrm{eV}$ at $120 \mathrm{~K}$, and deviates from linearity at temperatures below $120 \mathrm{~K}$. As can be seen from figure 5, the $\mathrm{BH}$ values calculated by Norde's method and $C^{-2}-V$ characteristics coincide with each other in the temperature range of $120-300 \mathrm{~K}$, but not at low temperatures below $120 \mathrm{~K}$. As 
indicated above, the $\mathrm{BH}$ values calculated from the $C-V$ data give an average value of the $\mathrm{BHs}$ of patches present in the Schottky contact. Thus, it can be said that Norde's method used to calculate the $\mathrm{BH}$ value in the ideal Schottky diodes gives approximately an average value of the $\mathrm{BHs}$ at each temperatures except for low temperatures [28, 42, 43]. The temperature coefficient of the $\mathrm{BH}$ can be also determined from this plot. The fitting to the $\Phi(T)$ data equation above yields a straight line with the slope of $\alpha=-0.51 \mathrm{meV} \mathrm{K}^{-1}$ called the temperature coefficient value of the BH. Thus, this result has been also confirmed by the temperature coefficient value (open triangles) of $\alpha=-0.54 \mathrm{meV} \mathrm{K}^{-1}$ from $C^{-2}-V$ curves in figure 4.

In conclusion, the $I-V$ characteristics of the device have almost given the diode parameters independent of the measurement temperature at temperatures above $130 \mathrm{~K}$. It can be said that the $\mathrm{Au} / \mathrm{Ti} / \mathrm{n}-\mathrm{GaAs} / \mathrm{In}$ diodes fabricated by the magnetron DC sputter technique are a candidate for electronic device applications. The $\mathrm{BH}$ value from the $I-V$ data of the device has increased from $0.77 \mathrm{eV}$ at $300 \mathrm{~K}$ to $0.82 \mathrm{eV}$ at $180 \mathrm{~K}$, and has remained at almost the same value in the $130-180 \mathrm{~K}$ range. Furthermore, it has been found that the experimental conventional RC value of the semiconductor substrate used in the fabrication of the Schottky diode is really in very close agreement with the theoretical RC value, because the $I-V$ characteristics of the device obey the TE current mechanism in the $120-300 \mathrm{~K}$ range. The capacitance versus temperature curves plotted as a function of the bias voltage characteristics have given four regions with different slopes at each bias voltage, and the slopes decrease with decreasing voltage from 0.20 to $-2.0 \mathrm{~V}$. A carrier concentration value of $7.43 \times 10^{15} \mathrm{~cm}^{-3}$ was calculated from the $C^{-2}-V$ plots around room temperature, which is close to the value given by the manufacturer.

\section{Acknowledgements}

This work was supported by Ataturk University (Project No: BAP 2011/365). The samples were prepared at Bilkent University UNAM. The authors wish to thank Ataturk University and Bilikent University UNAM.

\section{References}

[1] Saghrouni H, Hannachi R, Jomni S and Beji L 2013 Physica B 422 64-71

[2] Rhoderick E H and Williams R H 1988 Metal-Semiconductor Contacts 2nd edn (Oxford: Clarendon)

[3] Sze S M 1981 Physics of Semiconductor Devices 2nd edn (New York: Wiley)

[4] Lajn A, von Wenckstern H, Grundmann M, Wagner G, Barquinha P, Fortunato E and Martin R 2013 J. Appl. Phys. 113044511

[5] Korucu D and Duman S 2013 Thin Solid Films 531 436-41

[6] Jyothi I, Seo M-W, Janardhanam V, Shim K-H, Lee Y-B, Ahn K-S and Choi C-J 2013 J Alloys and Comp. 556 252-8
[7] Ahaitouf A, Srour H, Hamady S O S, Fressengeas N, Ougazzaden A and Salvestrini J P 2012 Thin Solid Films 522 345-51

[8] Ozavcı E, Demirezen S, Aydemir U and Altındal S 2013 Sensors and Actuators A 194259

[9] Goksu T, Yıldırım N, Korkut H, Ozdemir A F, Turut A and Kokce A 2010 Microelect. Engineer 871781

[10] Sehgal B K, Gulati R, Naik A A, Vinayak S, Rawal D S and Sharma H S 1997 Mater. Sci. Engineer. B 48229

[11] Sehgal B K, Bhattacharya B, Vinayak S and Gulati R 1998 Thin Solid Films 330146

[12] Arulkumaran S, Arokiaraj J, Dharmarasu N and Kumar J 1996 Nucl. Inst. Meth. Phys. Res. B 119519

[13] Di Dio M, Cola A, Lupo M G and Vasanelli L 1995 Solid-State Electron. 381923

[14] Gao W, Li Z and Sammes N 2011 An Introduction to Electronic Materials for Engineers 2nd edn (Singapore: World Scientific)

[15] Forment S, Biber M, Van Meirhaeghe R L, Leroy W P and Türüt A 2004 Semicond. Sci. Technol. 191391

[16] Janardhanam V, Kumar A A, Reddy V R and Reddy P N 2009 J. Alloys Comp. 485467

[17] Khuchua N P, Khvedelidze L V, Tigishvili M G, Gorev N B, Privalov E N and Kodzhespirova I F 2003 Russian Microelectronics 32 257-74

[18] Lakshmi B P, Reddy M S P, Kumar A A and Reddy V R 2012 Curr. Appl. Phys. 12765

[19] Turut A, Yalcin N and Saglam M 1992 Solid State Electron. 35 835-41

[20] Kundu S, Kumar A, Banerjee S and Banerji P 2012 Mater. Sci. Semicond. Process. 15386

[21] Saglam M and Turut A 1997 Semicond. Sci. Technol. 12 1028-31

[22] Vandenbroucke D A, Van Meirhaeghe R L, Laflere W H and Cardon F Semicond. Sci. Technol. 2 293-8

[23] Passler R 2002 Phys. Rev. B 66085201

[24] Thurmond C D 1975 J. Electrochem. Soc. 1221133

[25] Lautenschlager P, Garriga M, Logothetidis S and Cardona M 1987 Phys. Rev. B 359174

[26] Donoval D, Barus M and Zdimal M 1991 Solid State Electronics 34 1365-73

[27] Zhu S Y, Detavernier C, Van Meirhaeghe R L, Cardon F, Ru G-P, Qu X-P and Li B-Z 2000 Solid-State Electron. 441807

[28] Korucu D, Turut A and Efeoglu H 2013 Physica B 414 35-41

[29] Gammon P M et al 2013 J. Appl. Phys. 114223704

[30] Chand S, Kaushal P and Osvald J 2013 Mater. Sci. Semicon. Process. 16 454-60

[31] Tung R T 2014 Appl. Phys. Rev. 1011304

[32] Sullivan J P, Tung R T, Pinto M R and Graham W R 1991 J. Appl. Phys. 707403

[33] Osvald J 1999 J Apll. Phys. 851935

[34] Tunç T, Altindal Ş, Uslu İ, Dökme İ and Uslu H 2011 Mater Sci. Semicon. Process. 14139

[35] Osvald J and Horvath Z J 2004 Appl. Surf. Sci. 234 349-54

[36] Huang W-C, Lin T-C, Horng C-T, Li Y-H and Sci M 2013 Semicon. Process. 16418

[37] Tuğluoğlu N, Yüksel Ö F, Karadeniz S and Şafak H 2013 Mater. Sci. Semicon. Process. 16786

[38] Yildirim N, Dogan H, Korkut H and Turut A 2009 Int. J. Modern Phys. B 23 5237-49

[39] Kaushal P, Chand S and Osvald J 2013 Int. J. Electronics 100 686-98

[40] Tataroğlu A and Pür F Z 2013 Phys. Scr. 88015801

[41] Yildirim N, Korkut H and Turut A 2009 Eur. Phys. J. Appl. Phys. 4510302

[42] Norde H 1979 J. Appl. Phys. 505052

[43] Korkut H, Yildirim N and Turut A 2009 Microelect. Engineer 86 111-6 